\title{
Improving Preoperative Communication and First Case On-Time Starts with the Surgical Flight Plan: A Pilot Study
}

\author{
Reuben A. Falola, MD, MPH ${ }^{1}$ Nelson A. Rodriguez-Unda, MD ${ }^{1}$ Robert A. Probe, MD² \\ Harry T. Papaconstantinou, MD ${ }^{3}$ Michel H. Saint-Cyr, MD ${ }^{1}$ Andrew M. Altman, MD ${ }^{1}$
}

${ }^{1}$ Division of Plastic Surgery, Baylor Scott and White Medical Center, Temple, Texas

${ }^{2}$ Department of Orthopedic Surgery, Baylor Scott and White Medical

Address for correspondence Andrew Altman, MD, Baylor Scott and White Department of Surgery, 2401 S 31st Street, Temple, TX 76508 Center, Temple, Texas

${ }^{3}$ Department of Surgery, Baylor Scott and White Medical Center, Temple, Texas

J Reconstr Microsurg Open 2022;7:e1-e6.

\begin{abstract}
Keywords

- high reliability organization

- first case on-time start

- surgical team communication

Background Closed-loop communication is essential for managing a diverse surgical team. When new or unfamiliar members are present, as is common in shift-based perioperative care, challenges to effective communication can arise.

Methods We introduced the Surgical Flight Plan (SFP), a novel communication tool that informs surgical team members on procedural details in advance of surgery, at our tertiary academic center. The tool was made available in the electronic health record prior to surgery. The primary outcome assessed after application of the SFP was "patient-in-room to incision time." The secondary outcome was "improvement of communication in surgical teams" as assessed by a standardized (10-item) preintervention survey and a follow-up postintervention survey, given 3 months later. Data were gathered using Redcap software and statistical analysis was performed using SAS 9.4, significance was set at $p$-value less than 0.05

Results Thirty-six first-start, operative plastic surgery cases were included for the analysis (20 pre- and 16 postintervention). The average time from patient-in-room to surgical time out were 59.15 and 48.69 minutes pre-/postintervention respectively $(p<.0437)$. Sixty-one members of the surgical team responded to the survey, with the majority citing improved team communication.

Conclusion The SFP significantly improved first case on-time starts (FCOTS) and may improve surgical team communication, efficiency, safety, and overall patient care. Expanding the use of the instrument into other surgical specialties is needed to further validate its efficacy.
\end{abstract}

received

June 16, 2021

accepted after revision

November 3, 2021
DOI https://doi.org/

$10.1055 / \mathrm{s}-0042-1742468$. ISSN 2377-0813.

\footnotetext{
(C) 2022. The Author(s).

This is an open access article published by Thieme under the terms of the Creative Commons Attribution-NonDerivative-NonCommercial-License, permitting copying and reproduction so long as the original work is given appropriate credit. Contents may not be used for commercial purposes, or adapted, remixed, transformed or built upon. (https://creativecommons.org/ licenses/by-nc-nd/4.0/)

Thieme Medical Publishers, Inc., 333 Seventh Avenue, 18th Floor, New York, NY 10001, USA
} 
Health care organizations, much like the other High-Risk Organizations (HROs), including commercial aviation and the nuclear power sector, are similar in that they satisfy four main criteria: These organizations operate in unforgiving social and political environments, employ risky technologies that present potential for error, are limited in learning through experimentation due to the magnitude of consequences from errors or mistakes, and, in that, they employ complex processes and technologies to avoid potential failures. $^{1,2}$

It is within this atmosphere of multiple demands and potential complications that modern health care is delivered, challenging medical personnel, notably surgical teams, to find new and better ways to communicate. A pivotal point in health care safety awareness was the release of "To Err is Human," published by the Institute of Medicine, in $2000{ }^{3}$ This report brought to light major safety concerns in our nation's hospitals, namely medical errors leading to increased morbidity and almost 100,000 deaths annually. ${ }^{3}$ Since then, many efforts have been made in hospitals around the nation to prevent, recognize, and mitigate patient harm from error. ${ }^{4}$ The concept of utilizing a surgical checklist was championed by Atul Gawande at the Brigham and Women's Hospital and has since been shown to improve safety and prevent errors, decreasing adverse event by $36 \%$ and mortality by $47 \%{ }^{5,6}$

High reliability teams are characterized by solid systems of communication ${ }^{1,2}$ that aid in preventing medical mistakes. A cornerstone of effective and efficient communication within surgical teams is the dissemination of key strategic information regarding the surgical plan, in advance of surgery. As in aviation, a clear plan outlined at the outset can serve to clarify goals and unify the team prior to surgery.

In modern health care, the operating room (OR) serves as a significant revenue and cost center and is a high-risk environment. Efficiency in the OR is a crucial indicator for both the value of health care delivery and patient safety. Means of improving OR safety and efficiency include ensuring first case on-time starts (FCOTS), which can reduce unused OR time, set the tone for subsequent cases, and be used as a surrogate metric for preoperative communication in the OR.

The objective of this study is to implement and assess a novel communication instrument, the Surgical Flight Plan (SFP), as a tool to enhance surgical team communication, safety, and FCOTS operations at a large tertiary, academic teaching hospital.

\section{Methods}

After Institutional Review Board (IRB) approval, roll out of the surgical checklist was implemented in three phases. Phase 1: preimplementation survey, a 10-item, informal survey was sent to key members of the OR team (circulating OR nurses, surgical scrub technicians, and anesthesia personnel). The purpose of the survey was to assess the general impressions on the current quality of communication by surgical personnel in advance of a first-start cases. Phase 2: design and implementation, the SFP checklist was constructed to display key information about surgical cases that were important components of preoperative surgical team communication. The design of the checklist utilized simple, repetitive elements, based on chromatic principles for impactful visuals, and the delivery of information $^{7,8}$ (-Fig. 1). The SFP was then introduced into the patient's electronic health record (EHR) under the media tab the day prior to surgery (or Friday/weekend prior to Monday cases) and was accessible to anyone providing care for the patient. Phase 3: assessment, a focused, 8-item postintervention survey was sent to plastic and reconstructive surgery team personnel to assess the impact of the SFP checklist.

Twenty consecutive preintervention cases and 16 consecutive postintervention cases were included in this study, from a variety of plastic and reconstructive surgical procedures. Four patients were excluded from analysis given multiple surgical teams present during their operation (e.g., surgical oncology for mastectomy in combination with plastic surgery for immediate breast reconstruction). The primary outcome was the difference between the times of "patient-in-room" and the "incision time." The secondary outcome was improvement of communication in surgical teams, as recorded by follow-up survey. Data were gathered using the REDCap software and statistical analysis was performed using SAS 9.4 significance was set at $p<0.05$.

\section{Results}

\section{Case Timing}

Thirty-six first start plastic surgery cases were analyzed in this study (20 pre- and 16 postintervention). There was a significant decrease in the average "time in room" to "incision time" in the 16 cases preceded by the SFP intervention when compared with the 20 cases in the control group $(M=48.69$ vs. $59.15 ; p<0.0437)$.

\section{Preintervention Survey}

Sixty-one members of the surgical team responded the preoperative survey, including circulating nurses, scrub techs, and anesthesia providers. Survey respondents were asked to rate their understanding of the details of the surgical plan prior to entering the OR, how well the surgeon communicates with the team prior to entering the OR, and the degree to which their team functions as a unit on a scale from 1 to 10 (1-very poor and 10-very well). On average, the respondents rated the above survey items as 7.18, 5.05, and 6.54, respectively (-Table 1). Prior to the SFP intervention, the majority of respondents (93\%) believed that their preoperative understanding of the procedures in which they participate could be improved (-Table 1). Similarly, the majority (94.92\%) felt that they could render more effective help to patients if they could improve their preoperative understanding of the surgical plan (-Table $\mathbf{1}$ ). Prior to the SFP intervention, a majority of respondents (71.7\%) reported that they sometimes, often, or always find out which operation they will assist with on the morning of 


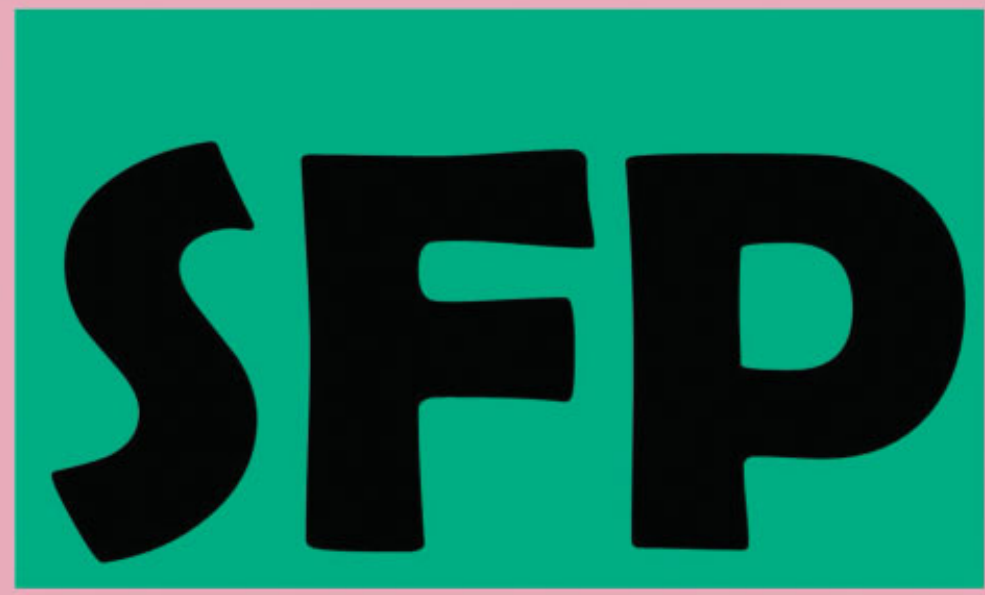

(Surgical flight plan)

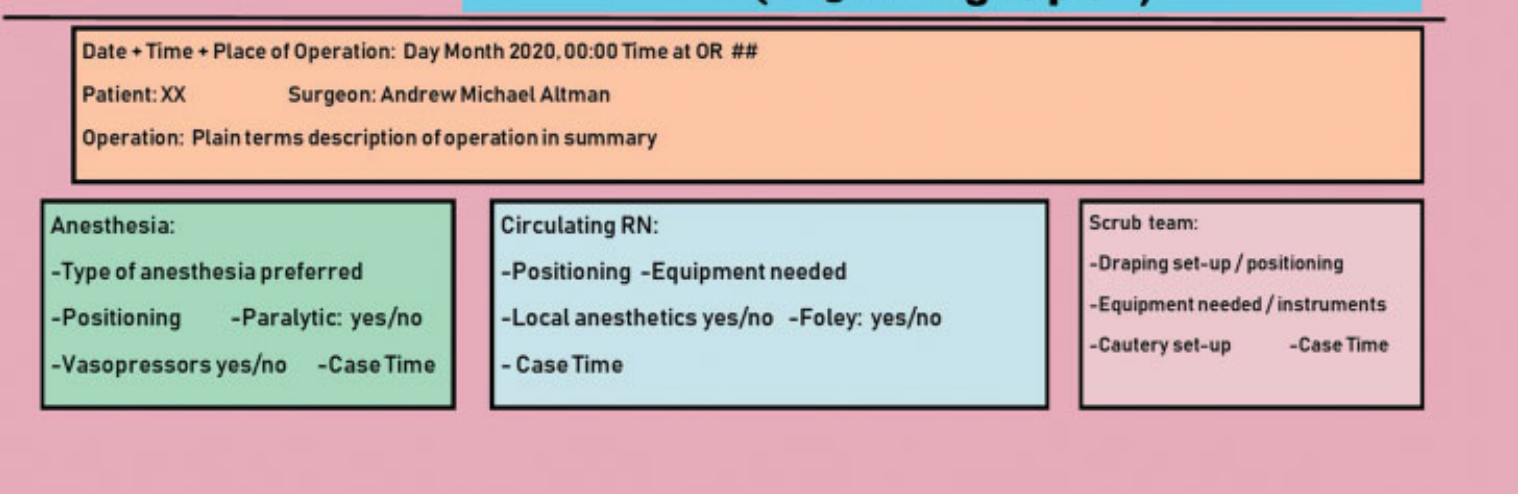

Fig. 1 The SFP checklist displays key information about surgical cases to improve preoperative surgical team communication. Simple, repetitive elements based on chromatic principles for impactful visuals and the delivery of information are utilized. SFP, the Surgical Flight Plan.

Table 1 Preoperative survey

\begin{tabular}{|l|l|l|}
\hline Survey item & Mean score (1-10) & $\begin{array}{l}\text { \% of } \\
\text { respondents (yes) }\end{array}$ \\
\hline $\begin{array}{l}\text { 1. How well do you understand the details of the surgical plan } \\
\text { at the time of entering the OR? }\end{array}$ & 7.18 & N/A \\
\hline $\begin{array}{l}\text { 2. How well does the surgeon communicate with you and your } \\
\text { team prior to entering the OR? }\end{array}$ & 5.05 & N/A \\
\hline $\begin{array}{l}\text { 3. To what degree do you feel the surgical team functions as a } \\
\text { cohesive unit? }\end{array}$ & 6.54 & N/A \\
\hline $\begin{array}{l}\text { 4. Do you feel your understanding of the surgeries in which } \\
\text { you participate can be improved prior to surgery? }\end{array}$ & N/A & 93.33 \\
\hline $\begin{array}{l}\text { 5. Do you feel like you could potentially help your patients } \\
\text { more effectively if you understood the surgery and plan } \\
\text { better prior to entering the OR? }\end{array}$ & N/A & 94.92 \\
\hline
\end{tabular}

Abbreviations: N/A, not available; OR, operating room.

${ }^{a} 1-$ very poor and $10-$ very well.

surgery (-Table 2). A majority (80\%) also reported that there is seldom or never communication between the surgeon and the surgical team prior to the morning of surgery (-Table 2 ). This was a source frustration at least sometimes in a majority (83.3\%) of survey respondents (-Table 2).

\section{Postintervention Survey}

Eighty-three percent of respondents found the SFP was very helpful for improving surgical team tasks (-Table 3 ). All respondents felt more prepared, safer, and more organized with the intervention (-Table $\mathbf{3}$ ). Furthermore, all respondents found that team communication and overall safety 
e4 Surgical Flight Plan for Improving Perioperative Communication Falola et al.

Table 2 Preoperative survey

\begin{tabular}{|c|c|c|}
\hline Survey item & Number & $\%$ of respondents \\
\hline \multicolumn{3}{|c|}{$\begin{array}{l}\text { 6. How often do you find out what operation you are helping } \\
\text { with before the morning of surgery? }\end{array}$} \\
\hline Always & 3 & 5 \\
\hline Often & 21 & 35 \\
\hline Sometimes & 19 & 31.67 \\
\hline Seldom & 12 & 20 \\
\hline Never & 5 & 8.33 \\
\hline \multicolumn{3}{|c|}{$\begin{array}{l}\text { 7. How often do you find out what operation you are helping } \\
\text { with the morning of surgery? }\end{array}$} \\
\hline Always & 14 & 23.33 \\
\hline Often & 20 & 33.33 \\
\hline Sometimes & 20 & 33.33 \\
\hline Seldom & 4 & 6.67 \\
\hline Never & 2 & 3.33 \\
\hline \multicolumn{3}{|c|}{$\begin{array}{l}\text { 8. How often does communication between the surgeon and } \\
\text { you and your team happen before the day of surgery? }\end{array}$} \\
\hline Always & 1 & 1.67 \\
\hline Often & 1 & 1.67 \\
\hline Sometimes & 10 & 16.67 \\
\hline Seldom & 20 & 33.33 \\
\hline Never & 28 & 46.67 \\
\hline \multicolumn{3}{|c|}{$\begin{array}{l}\text { 9. How often does communication between the surgeon and } \\
\text { you and your team happen the morning of surgery? }\end{array}$} \\
\hline Always & 19 & 31.67 \\
\hline Often & 26 & 43.33 \\
\hline Sometimes & 7 & 11.67 \\
\hline Seldom & 7 & 11.67 \\
\hline Never & 1 & 1.67 \\
\hline \multicolumn{3}{|c|}{$\begin{array}{l}\text { 10. How often are you frustrated by feeling that you have an } \\
\text { inadequate understanding of the surgery and plan prior to } \\
\text { the operation? }\end{array}$} \\
\hline Always & 0 & 0 \\
\hline Often & 10 & 16.67 \\
\hline Sometimes & 34 & 56.67 \\
\hline Seldom & 16 & 26.67 \\
\hline Never & 0 & 0 \\
\hline
\end{tabular}

were improved and felt more confident in the delivery of quality patient care after implementation of the checklist (-Table 3).

\section{Discussion}

High-reliability teams function with seamless lines of effective communication. Team members must be clear on their individual roles in addition to the unifying goal of the task at hand. The flight plan nomenclature was specifically chosen
Table 3 Postoperative survey

\begin{tabular}{|c|c|c|}
\hline Survey item & \multicolumn{2}{|c|}{$\%$ of respondents (yes) } \\
\hline Total respondents $(n=6)$ & \multicolumn{2}{|c|}{$\begin{array}{l}\text { All survey respondents } \\
(100 \%) \text { selected "Yes" } \\
\text { for questions } 1-7\end{array}$} \\
\hline \multicolumn{3}{|l|}{$\begin{array}{l}\text { 1. Did you feel like you were } \\
\text { more prepared for cases after } \\
\text { you had seen the Surgical } \\
\text { Flight Plan? }\end{array}$} \\
\hline \multicolumn{3}{|l|}{$\begin{array}{l}\text { 2. Did you feel like cases were } \\
\text { safer after you had seen the } \\
\text { Surgical Flight Plan? }\end{array}$} \\
\hline \multicolumn{3}{|l|}{$\begin{array}{l}\text { 3. Did you feel like cases were } \\
\text { more organized with the } \\
\text { Surgical Flight Plan? }\end{array}$} \\
\hline \multicolumn{3}{|l|}{$\begin{array}{l}\text { 4. Did you feel that the Surgical } \\
\text { Flight Plan improves surgical } \\
\text { teamwork? }\end{array}$} \\
\hline \multicolumn{3}{|l|}{$\begin{array}{l}\text { 5. Did you feel that the Surgical } \\
\text { Flight Plan improves surgical } \\
\text { team communication? }\end{array}$} \\
\hline \multicolumn{3}{|l|}{$\begin{array}{l}\text { 6. Do you feel that the Surgical } \\
\text { Flight Plan improves safety } \\
\text { overall? }\end{array}$} \\
\hline \multicolumn{3}{|l|}{$\begin{array}{l}\text { 7. Would standard use of the } \\
\text { Surgical Flight Plan make you } \\
\text { more confident in delivery of } \\
\text { quality patient care? }\end{array}$} \\
\hline & Number & $\begin{array}{l}\% \text { of } \\
\text { respondents }\end{array}$ \\
\hline \multicolumn{3}{|l|}{$\begin{array}{l}\text { 8. How helpful to your surgical } \\
\text { team tasks did you find the } \\
\text { Surgical Flight Plan? }\end{array}$} \\
\hline Very helpful & 5 & 83 \\
\hline Helpful & 1 & 17 \\
\hline Neutral & $\mathrm{N} / \mathrm{A}$ & N/A \\
\hline Somewhat helpful & $\mathrm{N} / \mathrm{A}$ & N/A \\
\hline Not helpful & $\mathrm{N} / \mathrm{A}$ & N/A \\
\hline
\end{tabular}

Abbreviation: N/A, not available.

to easily conjure a clear and culturally familiar mental image referencing flight crews pausing to discuss a plan prior to a journey, which easily parallels a surgical team in preparation. Challenges with the delivery of modern surgical care include frequent changes in personnel and the commoditization of time in the context of ever-present efficiency goals. Time pressures and team personnel heterogeneity are realities of health care delivery in the modern era and may be compounded in plastic and reconstructive surgery.

Because the above challenges are most evident within teams during the first cases of the day, the authors found this to be the setting most fertile for implementation of a checklist tool designed to unify the team and disseminate key information about the procedure in the critical 1-hour period ahead of surgery. The general feelings of the operative staff prior to SFP implementation were that they are often 
finding out the details of first start cases the morning of surgery, which is a cause for frustration. Respondents believed that team cohesion and patient care could be improved with better understanding of these key first start case elements.

Our series of 16 first cases utilizing the SFP instrument resulted in a positive reception from our surgical teams. The majority of participants state that all 8 metrics of communication, safety, and delivery of quality care were improved with implementation of the SFP.

Analysis of FCOTS demonstrated a decrease of 11.3 minutes on average in the SFP group compared with the historical controls $(p<0.0437)$. This difference is statistically significant but may be not considered clinically relevant. This study serves as proof of concept for a future, larger sample series which will help to further elucidate the effects of this useful tool. Further inquiry is needed to validate our findings, optimize the instrument, and maximize its impact, including expanding its use in different surgical specialties. Although confounding variables are certainly present, our data support enhanced clarity and communication within the surgical team and a trend toward decreasing barriers in communication, enhanced surgical efficiency, and improved safety.

A potential hurdle to wide adoption of a surgical checklist like the SFP is the need for a surgeon to input the case details into a computer-based form for subsequent upload into the EHR and access by other members of the surgical team. The entire process can require 10 to 15 minutes of time. In our experience, it is best to prepare the SFP the night before surgery, as operative plans can change from those discussed at the time of consultation in clinic. With so many demands placed on surgeons in the modern-day practice medicine, the addition of another duty can seem burdensome. Nonetheless, we found the process of creating the SFP a priceless moment for the surgeon to pause, reflect, plan, and organize in what was effectively a strategic "day before surgery" timeout, so to speak. It is important to appreciate the potential global benefit to the surgeon, surgical team, and health system when contemplating implementation of a surgical checklist. Key measures have been identified by the Centers for Medicare and Medicaid ${ }^{9}$ as uniform metrics for assessing the quality of health care delivery and for aligning reimbursements. Medicare and Medicaid contributions made up $37 \%$ of national health care expenditures in 2018, which was more than private health insurance (34\%), and more than any other individual category. ${ }^{10}$ By improving safety efforts in the OR, surgical checklists have the potential to directly and/or indirectly influence multiple CMS quality improvement programs including, but not limited to, the Hospital Readmissions Reduction Program, Hospital ValueBased Purchasing (VBP) Program, Hospital-Acquired Condition (HAC) Reduction Program, and survey-based metrics such as the Agency for Health Care Research and Quality (AHRQ) Hospital Survey on Patient Safety Culture. ${ }^{9}$ The benefits of the SFP and other checklists may be compounded by uniform adoption and increasing familiarity by surgeons and OR staff over time. With increasing familiarity comes a decreased time input, such that the surgical checklist may ultimately be viewed by surgeons as a minor tradeoff for significant benefits.

\section{Limitations}

The generalizability of our findings may be unclear, due to the low number of survey respondents and variability in response rates, ultimately producing a fragile $p$-value (0.043). Further, the difference between the preintervention and postintervention survey may be seen as a design flaw. As the study progressed, four key points stood out to the authors as follows: (1) there was confusion by some survey respondents on questions using the Likert scale (1-10), (2) questions assessing feelings on safety were lacking, (3) not all initial survey respondents were able to gain adequate experience using the survey instrument, and (4) the SFP, while tremendously informative, may still not be construed as communication with the provider by some OR staff. The decision was then made to create a simpler outcomes survey targeted at plastic surgery OR personnel who frequently utilized the SFP.

Future studies will utilize the SFP with a larger number of cases, both in plastic surgery and other surgical specialties. These studies will stratify by surgical specialty and type of case, tailor the SFP to optimize communication in each specific scenario, and ultimately provide an improved assessment of the benefits of this novel instrument.

\section{Conclusion}

The SFP is an innovative, low-cost communication tool that can improve the delivery of care in plastic and reconstructive surgery. The checklist can potentially improve OR efficiency and safety and has demonstrated improvements in first case on time starts at a tertiary academic hospital. Broad implementation of checklists can help to cultivate a culture of surgical communication, which may offset many challenges inherent to the complex, modern-day delivery of surgical care. Expanding implementation and including other surgical subspecialties will be necessary to further define and validate our findings.

\section{Funding \\ None. \\ Conflict of Interest \\ None declared.}

\section{References}

1 Roberts KH, Bea R. Must accidents happen? Lessons from highreliability organizations. Acad Manage Perspect 2001;15(03):70-78

2 Roberts KH, Rousseau DM. Research in nearly failure-free, highreliability organizations: having the bubble. IEEE Trans Eng Manage 1989;36(02):132-139

3 Kohn LT, Corrigan JM, Donaldson MS. Errors in health care: a leading cause of death and injury. In: To err is human: Building a safer health system. Washington, DC: National Academies Press (US); 2000 
e6 Surgical Flight Plan for Improving Perioperative Communication Falola et al.

4 Bates DW, Singh H. Two decades since to err is human: an assessment of progress and emerging priorities in patient safety. Health Aff (Millwood) 2018;37(11):1736-1743

5 Haynes AB, Weiser TG, Berry WR, et al; Safe Surgery Saves Lives Study Group. A surgical safety checklist to reduce morbidity and mortality in a global population. N Engl J Med 2009;360(05):491-499

6 Gawande A. Checklist Manifesto: How to Get Things Right. Haryana, India: Penguin Books India; 2010

7 Ware C. Information visualization: perception for design. Morgan Kaufmann2019
8 Lupton E, Miller JA, eds. ABC's of the Bauhaus: The Bauhaus and Design Theory. New York, USA: Princeton Architectural Press; 1991

9 Cms.gov. 2020Quality programs. Accessed July 15, 2020: https:// www.cms.gov/Medicare/Quality-Initiatives-Patient-AssessmentInstruments/MMS/Quality-Programs

10 Cms.gov. 2020NHE fact sheet. Accessed July 7, 2020: https:// www.cms.gov/Research-Statistics-Data-and-Systems/StatisticsTrends-and-Reports/NationalHealthExpendData/NHE-Fact-Sheet 